\title{
Profile of a liver transplant follow-up clinic in a nontransplant Canadian urban centre
}

\author{
R BAZYLEWSKI RN, BG ROSSER MD FRCPC, A COHEN MD, KDE KAITA MD FRCPC, GY MINUK MD FRCPC
}

\begin{abstract}
R BAZYLEWSKI, BG RosSer, A COHEN, KDE KAITA, GY MinuK. Profile of a liver transplant follow-up clinic in a nontransplant Canadian urban centre. Can J Gastroenterol 1997;11(3):235238. Care of the growing number of liver transplant recipients will increasingly fall on the referring centres. Thus, there is a need to define more clearly the demographic, clinical and laboratory profiles of liver transplant recipients, particularly in the setting of a centre where a liver transplantation program does not exist. The present study documented these features in 37 patients attending an adult ambulatory care clinic in an urban, nonliver transplant centre. Mean $\pm S D$ age of the study population was $44 \pm 11.9$ years. Twenty-one patients (57\%) were male. Annual enrolment in the clinic increased from three patients at the completion of the clinic's first year (1988) to 16 patients in the final year of the study (1993). Time between the transplantation procedure and the patient's return to the referring centre decreased from a mean of 12 weeks in 1988 to four weeks in 1993. During those seven years no patient required an unscheduled return to the transplant centre for surgical complications or problems associated with immunosuppressive therapy. In conclusion, these data provide a profile of liver transplant patients attending a nonliver transplant centre for follow-up and support the concept that nontransplant centres are capable of providing safe and, in terms of travel, less expensive care for liver transplant recipients.
\end{abstract}

Key Words: Cyclosporine, Follow-up, Immunosuppression, Liver disease, Liver transplant

\section{Profil d'une clinique pour les greffés du foie située dans un centre urbain canadien où l'on ne pratique pas de greffes}

RÉSUMÉ : Le suivi du nombre croissant de receveurs de transplantation hépatiques est appelé à relever des centres de références. Il faut donc définir plus clairement les profils démographiques cliniques et les résultats de laboratoire des receveurs de transplantation hépatique, surtout dans les centres où il n'existe pas de programmes de transplantation hépatique. La présente étude a rassemblé ces caractéristiques pour 37 patients inscrits à une clinique externe pour adultes d'un centre urbain où l'on ne pratique pas de transplantations hépatiques. L’âge moyen \pm é.-t. de la population étudiée, était de $44 \pm 11,9$ ans. Vingt-et-un patients (57\%) étaient de sexe masculin. Les inscriptions annuelles à la clinique ont augmenté, de trois patients à la fin de la première année de fonctionnement de la clinique (1988), à 16 patients au moment de la dernière année de l'étude (1993). Le temps écoulé entre la transplantation et le retour du patient au centre de références a diminué en moyenne de 12 semaines en 1988, à quatre semaines en 1993. Au cours de ces sept années, aucun patient n'a dû retourner au centre de transplantation sans rendez-vous à cause de complications chirurgicales ou de problèmes associés au traitement immunosuppresseur. En conclusion, ces données résument le profil des patients greffés du foie suivis dans un centre où on ne pratique pas de transplantations hépatiques et appuient la notion selon laquelle de tels centres peuvent offrir des soins sécuritaires et moins coûteux pour les greffés en termes de déplacement.
$\mathrm{L}$ iver transplantation represents an established therapy for patients with advanced liver disease. Although patient profiles and postoperative problems occurring at transplant sites have been described (1-3), there is a paucity of data regarding these issues from nontransplant centres where more frequent and less costly (in terms of travel) patient surveillance is available. We describe various demographic and clinical features of a liver transplant follow-up clinic established at a Canadian urban centre where liver transplants are not performed.

Liver Diseases Unit, Departments of Nursing, Medicine and Pharmacology, Health Sciences Centre; and University of Manitoba, Winnipeg, Manitoba

Correspondence and reprints: Dr GY Minuk, Liver Diseases Unit, GF407, Health Sciences Centre, 820 Sherbrook Street, Winnipeg, Manitoba R3A 1R9. Telephone 204-787-4662, fax 204-775-4255, e-mail gminuk@cc.umanitoba.ca

Received for publication May 7, 1996. Accepted September 6, 1996 


\section{PATIENTS AND METHODS}

The medical records of 37 patients returning to the Health Sciences Centre in Winnipeg, Manitoba from transplant centres elsewhere in Canada and the United States between July 1, 1987, the inception of the adult liver transplant follow-up clinic at the Health Sciences Centre, and January 1, 1994 were reviewed. The following information was obtained from each record: age at transplant, sex, underlying liver disease, site of transplant, duration of time elapsed between the transplant procedure and return to the clinic, date of clinic enrolment, body weight, prevalence of liver enzyme abnormalities, number of medications taken at time of enrolment into the clinic, duration of time between the transplant procedure and return to full household or employment duties, number of patients on antihypertensive medications, serum cyclosporine trough levels, number and time of graft rejection episodes, and number and reasons for admission to hospital from the time of enrolment into the clinic. Care of the patients enrolled in the clinic was directed by a staff hepatologist and transplant nurse. The timing of follow-up visits was weekly for the first month, every two weeks for the next two months and monthly thereafter until one year post-transplant. Patients with normal liver enzyme tests were then seen every three months while those with abnormal liver enzyme tests were seen every two months (or more frequently if necessary). This schedule applied to all patients with the exception of a patient residing $420 \mathrm{~km}$ from Winnipeg, who after 15 months was seen every six months at the transplant follow-up clinic, with her family physician reviewing her status at the other time points. All liver biopsies, regardless of a patient's distance from the clinic, were performed at the clinic centre. Although the appropriate transplant centres were kept informed regarding patient problems and admissions, the transplant centres were rarely involved in initiating patient management decisions.

The Health Sciences Centre is an 1100-bed tertiary care centre serving a referral population of approximately 1.25 million individuals. At the time of this study, the centre offered transplantation surgery and follow-up for patients with kidney and eye disorders. Heart transplant recipients tended to be followed in a renal transplant follow-up clinic. A liver diseases unit also located within the centre followed approximately 1000 patients with acute or chronic liver disorders (4).

Statistical analyses were performed using Student's $t$ test for paired or unpaired data as appropriate. All results are reported as mean $\pm \mathrm{SD}$. $\mathrm{P}<0.05$ was considered significant.

\section{RESULTS}

Since its inception in 1987 there has been a significant increase in the number of patients attending the liver transplant follow-up clinic (Figure 1). As of January 1, 1994, 39 patients were being followed. All but one patient had returned directly from a transplant centre. The one exception was a patient referred by a physician in the community who had been following that patient post-liver transplant in an

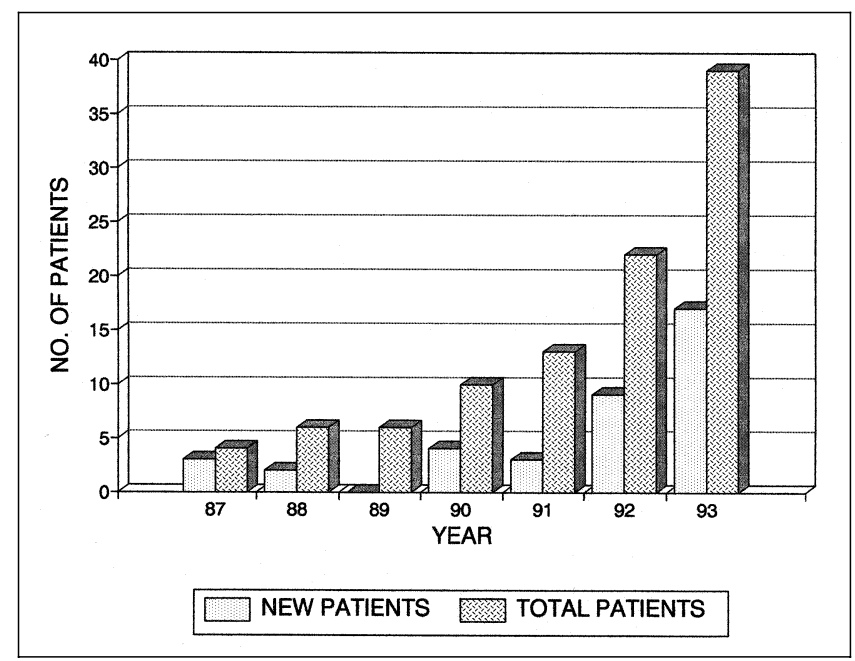

Figure 1) Number of patients enrolled and year of enrolment in the liver transplant follow-up clinic

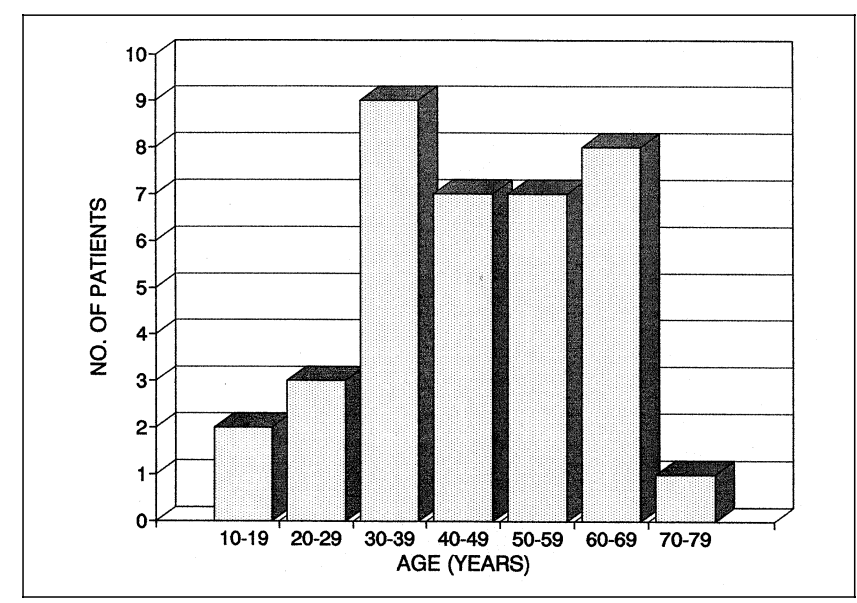

Figure 2) Distribution of ages at time of transplantation in patients attending the liver transplant follow-up clinic

office setting. Mean duration of follow-up for the 37 patients was $1.8 \pm 1.7$ years (range three months to seven years). Two deaths occurred during the follow-up. A 39-year-old male died 51 months post-transplant from liver failure related to a recurrent hepatitis $B$ virus infection and a 58-year-old male died five months after transplant from metastatic cancer of the colon. Of the remaining 37 patients who continued to attend the clinic and form the basis of this study, 21 (57\%) were male and $16(43 \%)$ female. Mean \pm SD age was $42.5 \pm 16.0$ years for males and $49.1 \pm 14.9$ years for females. Twenty-nine patients resided in greater Winnipeg while eight lived between 30 and $882 \mathrm{~km}$ from the city.

Figure 2 indicates the age of patients by decade at transplantation. The majority of patients were between 30 and 70 years old at transplantation. The youngest patient was 10 and the oldest was 71. Underlying liver disease was primary biliary cirrhosis in nine, primary sclerosing cholangitis in seven, alcohol-induced liver failure in six, hepatitis $\mathrm{C}$ virus infection in five, Wilson's disease in three and miscellaneous in seven (Figure 3). All but seven of the transplant procedures 


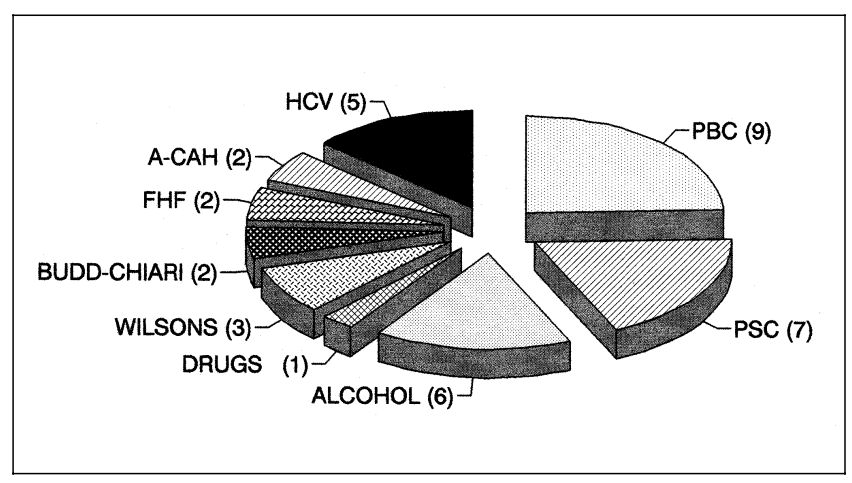

Figure 3) Causes of underlying liver disease that resulted in liver transplantation. Numbers in parentheses indicate numbers of patients. A-CAH Autoimmune chronic active hepatitis; FHF Fulminant hepatic failure; HCV Hepatitis C virus; PBC Primary biliary cirrhosis; PSC Primary sclerosing cholangitis

took place in London, Ontario, with two each performed in Toronto, Edmonton and Vancouver, and one in Pittsburgh, Pennsylvania.

As shown in Table 1, time between the transplant procedure and discharge to the referring centre decreased from an average of 12 weeks for those transplanted in 1987 and 1988, to four weeks for those transplanted in 1993. The percentage of patients with elevated liver enzymes at enrolment in the clinic also decreased from approximately $75 \%$ to $35 \%$ over the same period. The average number of medications taken per patient at the time of enrolment in the clinic remained stable at approximately five drugs per patient. Most common medications included cyclosporine A, prednisone, azathioprine, an antihypertensive and mineral supplements, with cyclosporine A altered to provide trough levels between 250 and $300 \mu \mathrm{g} / \mathrm{L}$ during the initial six months, between 200 and $250 \mu \mathrm{g} / \mathrm{L}$ for the next six months and between 150 and $200 \mu \mathrm{g} / \mathrm{L}$ thereafter.

Eight of 24 patients (33\%) employed outside the home before transplantation returned to their previous positions after a mean of 9.1 months (range two to 24). The majority of these patients (six of eight [75\%]) resumed full activity within six months of transplantation.

There was a significant increase in body weight from time of enrolment into the clinic to the most recent weight recorded $(65.4 \pm 11.6$ versus $75.4 \pm 14.9 \mathrm{~kg}, \mathrm{P}<0.005)$.

The number of patients receiving antihypertensive therapy as a function of time from transplantation is depicted in Figure 4. Eight of the nine patients followed for at least four years were receiving antihypertensive therapy, and by six years all five patients were receiving such therapy. Trough serum cyclosporine levels fell during the course of follow-up from a mean of $275 \pm 46 \mu \mathrm{g} / \mathrm{L}$ at enrolment to $210 \pm 67 \mu \mathrm{g} / \mathrm{L}$ at the last recorded visit $(\mathrm{P}<0.05)$. In general creatinine levels remained within the range of 125 to $160 \mu \mathrm{mol} / \mathrm{L}$ (normal 70 to $110 \mu \mathrm{mol} / \mathrm{L}$ ) throughout follow-up.

Twelve patients (32\%) were treated for episodes of rejection. The mean time from enrolment into the clinic to the first episode of rejection was $8.2 \pm 4.2$ months (range two to
TABLE 1

Time from transplantation to discharge to referring centre

\begin{tabular}{lcc}
\hline Year & Number of patients & Time (weeks) \\
\hline 1987 & 3 & 12 \\
1988 & 2 & 8 \\
1989 & 0 & N/A \\
1990 & 4 & 13 \\
1991 & 3 & 9 \\
1992 & 9 & 8 \\
1993 & 16 & 4 \\
\hline
\end{tabular}

N/A Nonapplicable

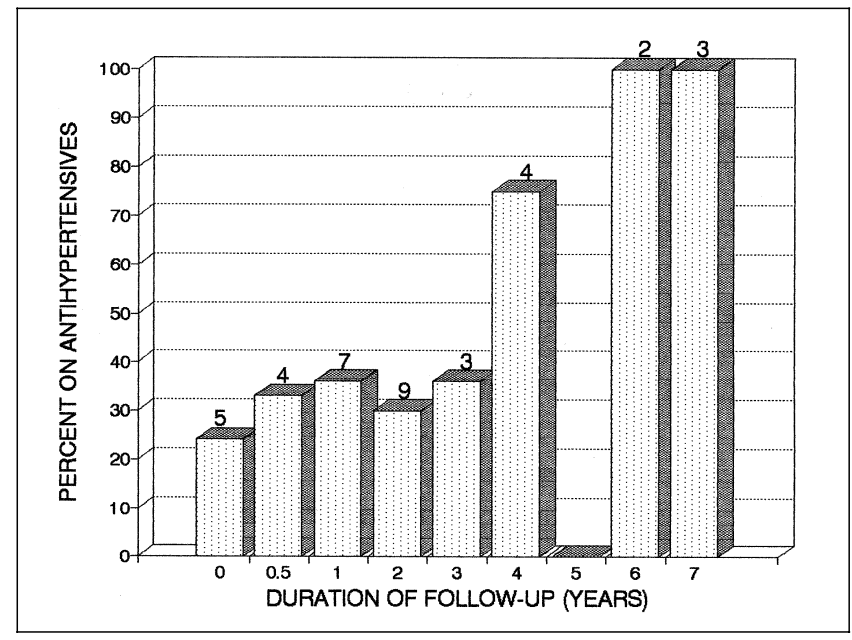

Figure 4) Percentage of patients receiving antihypertensive medications. Numbers at top of each bar represent the numbers of patients followed for the time indicated

15). All patients responded to increases in corticosteroid therapy (methylprednisolone 250 to $500 \mathrm{mg}$ for three days followed by rapid tapering to maintenance levels, or prednisone $50 \mathrm{mg} /$ day for five days decreased by $5 \mathrm{mg}$ every third day until maintenance at 7.5 to $15 \mathrm{mg} /$ day). Admissions to hospital for rejection or other medical problems were required for 17 patients (46\%). Reasons for admission could be categorized as hepatobiliary problems (10 admissions), suspected or confirmed infections (10), surgical procedures (six) and miscellaneous (five).

\section{DISCUSSION}

One of the more striking findings in this study was the increase in the number of patients followed at our centre over the past seven years. Although the reason for the increase is unclear, a number of factors must be considered. First, there had been a parallel increase in the number of patients attending the associated liver diseases out-patient clinic at our institution. Thus, increased patient referral was likely a major contributing factor. Second, the indications for liver transplantation have been modified in recent years such that certain patients with alcohol- and viral-induced liver failure who would not have been considered transplant candidates in previous years are currently being transplanted (5). Third, the results may reflect a gradual acceptance by general practitioners and 
specialists that liver transplantation is now a viable therapeutic option for patients who would otherwise have been allowed to succumb to complications of advanced liver disease. Finally, increased donor awareness, the advent of split liver grafts and improved surgical outcomes have all contributed to more patients being successfully transplanted and, hence, more patients returning to their referring centre (6).

The impression that patients are being discharged from transplant centres earlier than was previously done raised concerns regarding the status of these patients on arrival at the follow-up clinic. Although results of this study confirmed the impression that patients were being discharged earlier, concerns about their clinical status appear to have been unfounded; the percentage of patients with liver enzyme abnormalities at enrolment into the clinic had not increased - in fact had decreased - over this period. Moreover, the number of medications taken per patient, which may serve as a surrogate marker of disease states $(7,8)$, remained relatively stable at five medications per patient.

The most recent study describing re-employment following liver transplantation reported that $40 \%$ of patients returned to full daily activities within one year of liver transplantation (9). Results at our centre (eight of 28 patients [29\%]) were somewhat lower than that predicted. Reasons for the low rate are not clear. Employment figures for the city and province in which the clinic is located were similar to or higher than the national average over the seven-year period covered by this study. Thus, regional unemployment is not applicable. Age of the patient population, which previously has been reported to correlate inversely with the time elapsed to return to work, was not advanced, relative to published figures from other transplant centres (9). There was no disproportionate increase in the number of female transplant recipients (for whom return to full activity is less common) (10). Unfortunately, we do not have data regarding the duration of time away from work before transplantation, which correlates best with resumption of activity in the post-transplant setting (9).

Significant increases in the body weights of transplant recipients have been described previously (11). Weight gain is thought to result from a combination of improved wellbeing, recovery from pretransplant malnourishment, fewer dietary restrictions and effects of corticosteroid therapy. Fluid retention problems, which represent an additional cause of weight gain in this setting, were not seen in any of our transplant recipients.

Eight of the nine patients followed for four years or longer were receiving antihypertensive therapy. While the cause of the hypertension in these individuals is likely related to the vascular effects of cyclosporine, renal dysfunction and preexisting hypertension must also be considered. Neither alternative explanation appears to be applicable in this instance because serum creatinine levels were stable and none of the patients had pretransplant histories of hypertension. Indeed, three were hypotensive in the year before transplant. When required, calcium channel blockers were employed as antihypertensive medication due to their more limited interac- tion with cyclosporine and their predicted protection against the adverse effects of cyclosporine on the systemic vasculature (12).

Despite that allograft rejection is most common within the three months immediately following liver transplantation, we identified 12 histologically documented episodes of rejection requiring alterations in immunosuppressive therapy at various times after transplant. These episodes were not associated with decreases in serum cyclosporine levels and responded promptly to pulse steroid therapy. They constituted the majority of reasons for admission to hospital for hepatobiliary problems. With the exception of two hospitalizations in which one patient underwent a hysterectomy and another a bladder neck suspension, other reasons for admission (infection, surgery and miscellaneous) were associated with the transplant procedure.

The growing number of patients enrolled in this clinic and the frequency, diversity and complexity of the problems encountered highlight the need for a multidisciplinary team approach to managing this particular patient population. That team should include physicians with expertise in liver disease, pathologists, infectious disease specialists, surgeons, nurses and full paramedical support staff. The team should communicate openly with the transplant centre to ensure that the appropriate data are exchanged in an efficient and useful manner in order to alleviate patient concerns regarding their departure from a centre that 'gave them life' to the site they commonly associate with their life-threatening illness.

\section{CONCLUSIONS}

This study describes the patient profile and clinical features of an urban liver transplant follow-up clinic where liver transplants are not being performed. The data support the concept that long term follow-up care for liver transplant recipients can be carried out in a safe and, in terms of travel, less costly manner by referral centres without liver transplant programs.

\section{REFERENCES}

1. Starzl TE, Demetris AJ, Van Thiel D. Liver transplantation. N Engl J Med 1989;321:1014-22, 1092-9.

2. Maddrey WC, Van Thiel DH. Liver transplantation: An overview. Hepatology 1988;8:948-59.

3. Bismuth H, Castaing D, Ericzon GB, et al. Hepatic transplantation in Europe. Lancet 1987;ii:675-6.

4. Byron D, Minuk GY. Clinical hepatology: profile of an urban, hospital-based practice. Hepatology 1996;24:813-5.

5. Sorrell MF, Donovan JP, Byers WS Jr. Transplantation in the alcoholic: a stalking horse for a larger problem. Gastroenterology 1992;102:1806-8.

6. Heffron TG. Living related liver transplantation. Semin Liver Dis 1995; 15:165-72.

7. Krach P, Yang J. Functional status of older persons with chronic mental illness living in a home setting. Arch Psychiatr Nurs 1992;6:90-7.

8. Von-Korff M, Wagner EH, Saunders K. A chronic disease score from automated pharmacy data. J Clin Epidemiol 1992;45:197-203.

9. Adams PC, Ghent CN, Grant DR, Wall WJ. Employment after liver transplantation. Hepatology 1995;21:140-4

10. Wingard JR, Curbow B, Baker F, Piantadosi S. Health, functional status, and employment of adult survivors of bone marrow transplantation. Ann Intern Med 1991;114:113-8.

11. Hasse J. Role of the dietitian in the nutrition management of adults after liver transplantation. J Am Diet Assoc 1991;91:473-6.

12. Epstein M. Calcium antagonists and the kidney. J Cardiovasc Pharmacol 1994;24:S18-24. 


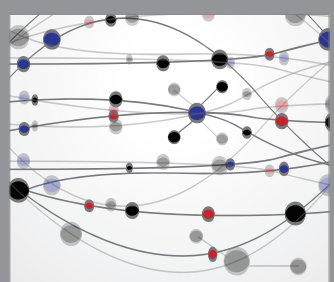

The Scientific World Journal
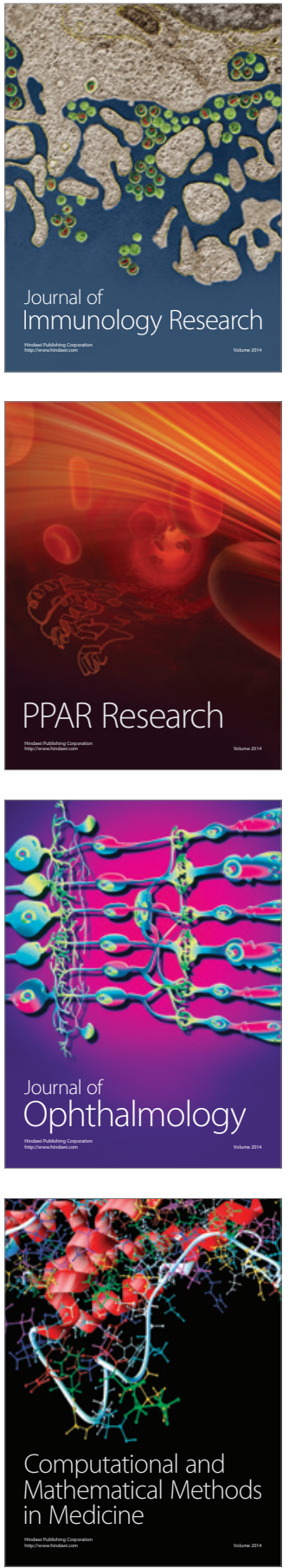

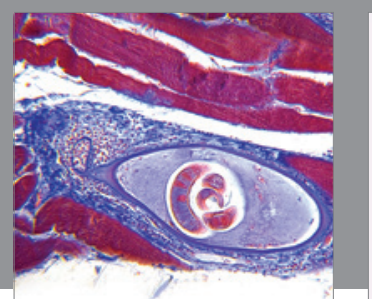

Gastroenterology Research and Practice

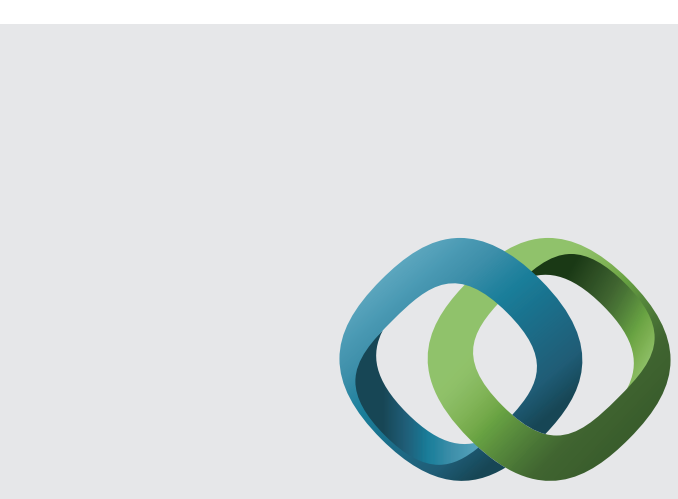

\section{Hindawi}

Submit your manuscripts at

http://www.hindawi.com
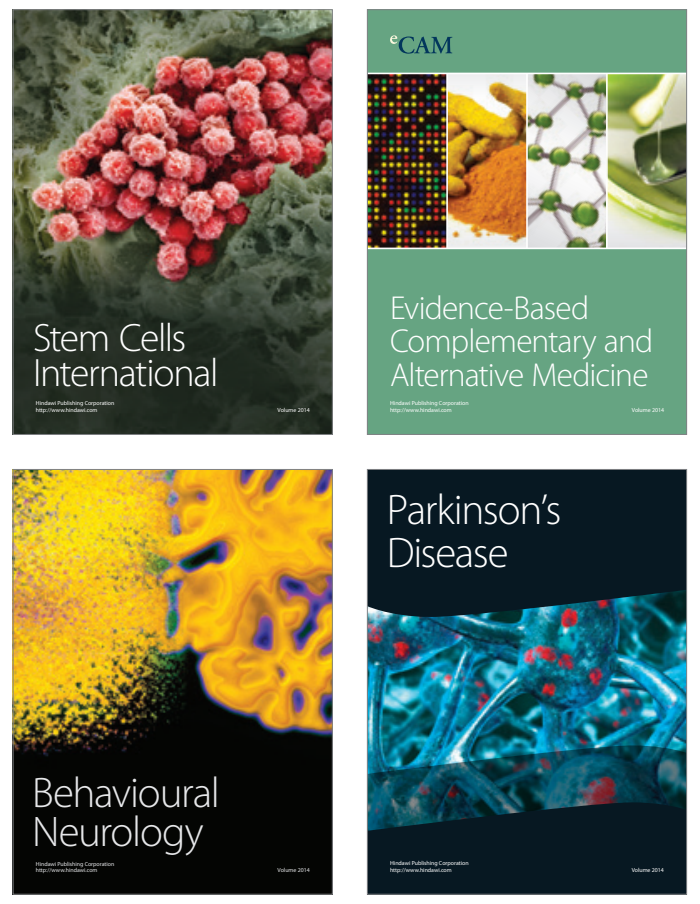
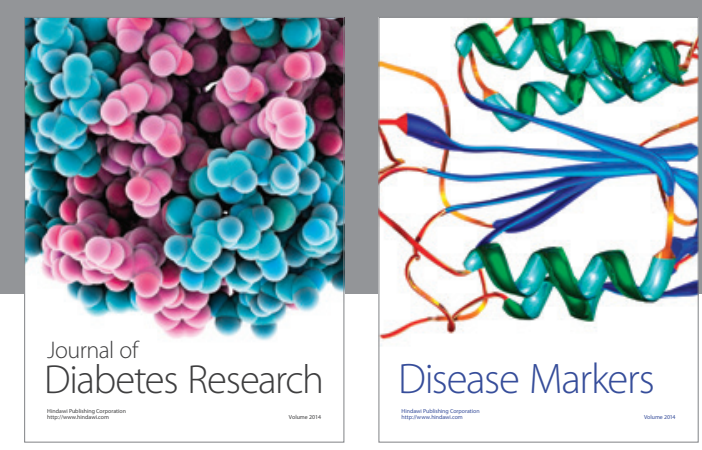

Disease Markers
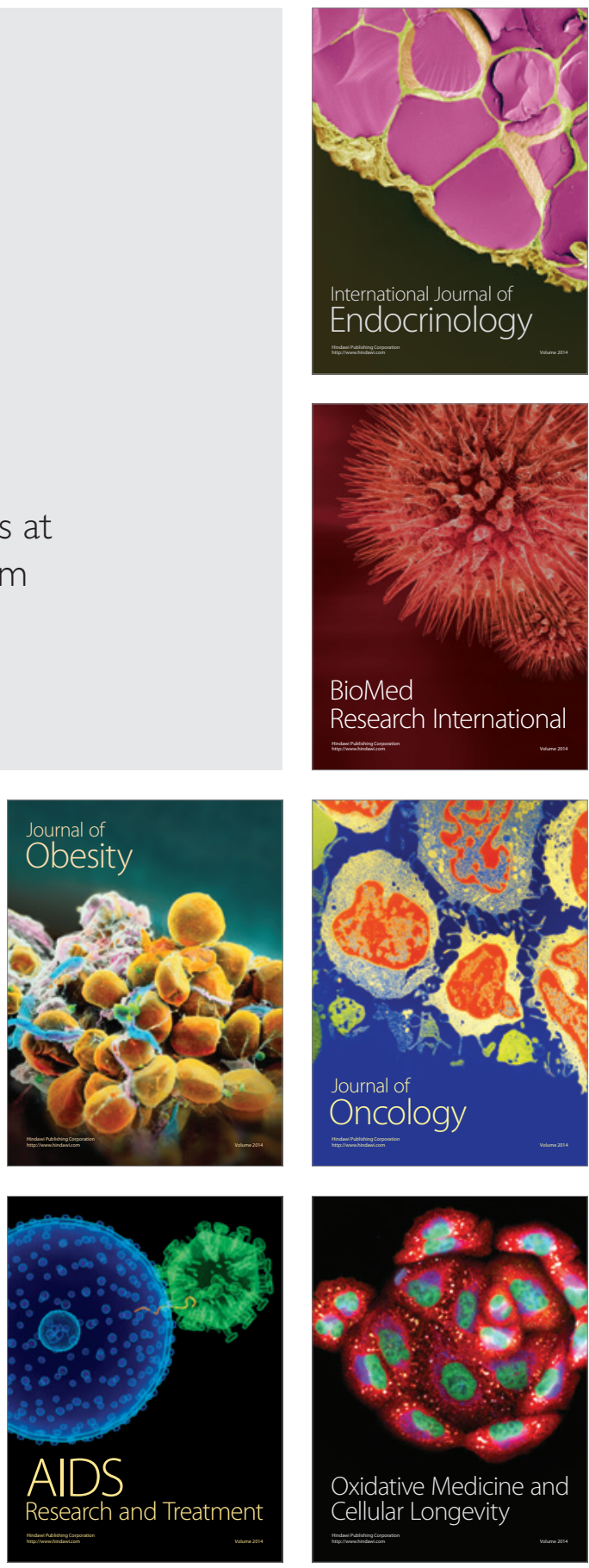